Gut, 1983, 24, 845-852

Progress report

\title{
Factors affecting morbidity and mortality after surgery for obstructive jaundice: a review of 373 patients
}

A retrospective study of 373 patients undergoing surgery for relief of bile duct obstruction identified three independent factors associated with increased postoperative morbidity and mortality. These three factors were: (i) an initial haematocrit of $30 \%$ or less; (ii) an initial plasma bilirubin of greater than $200 \mu \mathrm{mol} / \mathrm{l}$; (iii) a malignant obstructing lesion. The presence of two or all three of these risk factors identified a group of patients with a one third postoperative mortality and it is in this group of patients that preliminary non-operative or definitive non-operative biliary drainage might prove most useful.

Surgery for obstructive jaundice continues to be associated with significant morbidity and mortality despite recent advances both in preoperative diagnosis and postoperative care. ${ }^{12}$ Several studies have identified preoperative factors which define groups of patients at high risk of postoperative mortality ${ }^{3-5}$ and it has been suggested that mortality in these high risk groups might be reduced by the use of the newly available techniques of external or internal drainage of the obstructed biliary tree. ${ }^{16-8}$ The most comprehensive study identified eight preoperative factors which were associated with increased postoperative morbidity and mortality. ${ }^{3}$ The authors, however, did not take into account the effect of the operative procedure performed, half of all the deaths occuring in the minority of patients undergoing the most extensive surgical procedures, nor did they assess any interrelation of the eight risk factors.

A retrospective study was undertaken to assess effect of preoperative and operative parameters on postoperative outcome. It was the aim of our study to identify those factors which were independently associated with an increased risk of postoperative morbidity and mortality and which may be useful in predicting patients likely to benefit from preoperative and non-operative biliary drainage.

\section{Methods}

PATIENTS

Three hundred and seventy three patients with clinical jaundice (plasma bilirubin of greater than $50 \mu \mathrm{mol} / \mathrm{l}$, normal range $2-18 \mu \mathrm{mol} / \mathrm{l}$ ) who underwent surgery for relief of bile duct obstruction during the period 1976-81 in the department of Clinical Surgery, Royal Infirmary, Edinburgh were identified and a full review of all clinical case records undertaken. 
Table 1 Operative procedures performed in 373 patients with obstructive jaundice

\begin{tabular}{ll}
\hline 281 patients with benign obstruction & \\
\hline $255:$ cholecystectomy + & -214 supraduodenal exploration \\
exploration of common bile duct & $\begin{array}{c}-41 \text { combined supraduodenal }+ \\
\text { transduodenal exploration }\end{array}$ \\
$10:$ exploration of common bile duct only & \\
$12:$ simple bypass & \\
$4:$ resection of stricture & \\
92 patients with malignant obstruction & \\
\hline $6:$ Whipple's procedure \\
$2:$ hepaticojejunostomy \\
$71:$ cholecystenterostomy \\
$13:$ choledochoenterostomy
\end{tabular}

Of the 373 patients, 281 had a benign and 92 a malignant cause of obstruction. The operative procedures performed in these two groups of patients are listed in Table 1 . Two hundred and seventy of the operations were performed by a consultant surgeon, 91 by a senior registrar and 12 by a registrar. All patients received parenteral mannitol and vitamin $\mathbf{K}_{1}$ before surgery. A total of 186 patients received antibiotics preoperatively, this being determined by the patient's clinical state and the wishes of the consultant in charge.

Full clinical, laboratory, and operative data were collected for all patients. Any postoperative complication was noted as was the date and cause of death. For the purposes of this study postoperative mortality was defined as death within 30 days of operation or death during the same hospital admission. Data on the following postoperative complications were available; renal failure, gastrointestinal bleeding, wound infection, wound dehiscence, septicaemia, abdominal abscess, and postoperative pancreatitis. Renal failure was defined as a rising urea in the postoperative period despite adequate fluid replacement. Gastrointestinal bleeding was noted as a complication only where the total measureable blood loss exceeded $500 \mathrm{ml}$.

Table 2 Risk factors studied in group of 373 patients with obstructive jaundice

\begin{tabular}{|c|c|}
\hline $\begin{array}{l}{ }^{*} \text { Age } \\
{ }^{*} \text { Sex } \\
{ }^{*} \text { Pancreatitis } \dagger \\
{ }^{*} \text { Diabetes } \\
{ }^{*} \text { Haematocrit } \\
{ }^{*} \text { ESR }\end{array}$ & 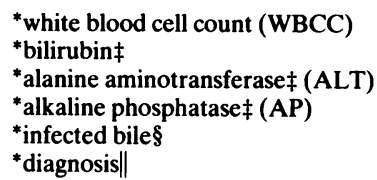 \\
\hline $\begin{array}{l}\text { Length of history } \\
\text { Weight loss } \\
\text { Abdominal pain } \\
\text { History of smoking } \\
\text { History of chest problems }\end{array}$ & $\begin{array}{l}\text { Pyrexia } \\
\text { Platelet count } \\
\text { Prothrombin time ratio } \\
\text { Albumin } \ddagger \\
\text { Urea } \ddagger\end{array}$ \\
\hline
\end{tabular}

* One of the 12 risk factors studied in every patient.

$\dagger$ A history of previous pancreatitis before admission.

$\ddagger$ Measured in plasma.

$\S$ Bile swabs taken in every case and where a positive growth was obtained patients were considered to have infected bile.

|| Final diagnosis of benign or malignant obstruction. 
In an initial group of 120 patients, the relationship of 22 clinical, laboratory, and operative parameters to postoperative morbidity and mortality was analysed. A group of 12 factors was identified for more extensive study in the total group of 373 patients. Table 2 lists all 22 factors analysed, the 12 extensively studied being listed first. All biochemical and haematological values were those from the initial blood sample taken at the time of admission and in every case before the institution of any form of treatment. A number of patients with low haematocrits received preoperative blood transfusion.

The statistical methods used in the analysis were: (i) multiple logistic regression to test the relationship of preoperative factors and postoperative

Table 3 Risk factors and their relationship to postoperative mortality when fitted alone

\begin{tabular}{|c|c|c|c|}
\hline Risk factor & Patients (\%) & Mortality (\%) & Significance \\
\hline \multicolumn{4}{|l|}{ Age } \\
\hline 60 or less & 34 & $3 \cdot 9$ & \\
\hline$>60$ & 66 & $13 \cdot 4$ & $\mathrm{p}<0.05$ \\
\hline \multicolumn{4}{|l|}{ Sex } \\
\hline Female & 63 & $7 \cdot 3$ & \\
\hline Male & 37 & $12 \cdot 2$ & NS \\
\hline \multicolumn{4}{|l|}{ Pancreatitis } \\
\hline Yes & 8 & $0 \cdot 0$ & \\
\hline No & 92 & $9 \cdot 9$ & NS \\
\hline \multicolumn{4}{|l|}{ Diabetes } \\
\hline No & 93 & $7 \cdot 2$ & \\
\hline Yes & 7 & $34 \cdot 5$ & $\mathrm{p}<0 \cdot 0005$ \\
\hline \multicolumn{4}{|c|}{ Hacmatocrit $(35-54 \%)^{*}$} \\
\hline$>30$ & 82 & $2 \cdot 3$ & \\
\hline 30 or less & 18 & $40 \cdot 9$ & $\mathrm{p}<0 \cdot 0005$ \\
\hline \multicolumn{4}{|l|}{ ESR } \\
\hline 50 or less & 75 & $7 \cdot 1$ & \\
\hline$>50$ & 25 & $15 \cdot 2$ & $\mathrm{p}<0.05$ \\
\hline \multicolumn{4}{|c|}{ WBCC $\left(4-10 \times 10^{9} / 1\right)^{*}$} \\
\hline $10 \times 10^{9} / 1$ or less & 72 & $7 \cdot 4$ & \\
\hline$>10 \times 10^{9} / 1$ & 28 & $13 \cdot 6$ & NS \\
\hline \multicolumn{4}{|c|}{ Bilirubin $(2-18 \mu \mathrm{mol} / \mathrm{l})^{*}$} \\
\hline 200 or less & 73 & $3 \cdot 7$ & \\
\hline$>200$ & 27 & $23 \cdot 5$ & $\mathrm{p}<0 \cdot 0005$ \\
\hline \multicolumn{4}{|l|}{$\operatorname{ALT}(20-40 \mathrm{U} / 1)^{*}$} \\
\hline 100 or less & 68 & $6 \cdot 3$ & \\
\hline$>100$ & 32 & $15 \cdot 0$ & $\mathrm{p}<0 \cdot 01$ \\
\hline \multicolumn{4}{|c|}{ AP $(100-400 \mathrm{U} / \mathrm{l})^{*}$} \\
\hline 100 or less & $\begin{array}{l}33 \\
67\end{array}$ & $\begin{array}{r}0.8 \\
13 \cdot 1\end{array}$ & $\mathrm{p}<0.01$ \\
\hline$>100$ & $0 /$ & & \\
\hline \multicolumn{4}{|l|}{ Infected bile } \\
\hline Yes & 40 & $8 \cdot 7$ & \\
\hline No & 60 & $9 \cdot 4$ & NS \\
\hline \multicolumn{4}{|l|}{ Disease } \\
\hline Benign & 75 & $3 \cdot 7$ & \\
\hline Malignant & 25 & $26 \cdot 1$ & $\mathrm{p}<0.0005$ \\
\hline
\end{tabular}

* Normal ranges shown in brackets. 
mortality, (ii) Chi-squared tests to analyse the relationship of postoperative complications and mortality and the relationship of preoperative factors and postoperative complications, and (iii) Fisher's exact test where numbers were small.

\section{Results}

There were 34 deaths within 30 days of operation giving a hospital mortality of $9 \cdot 1 \%$. The operative procedure performed had no effect on postoperative mortality, with only one death occurring in the group of patients undergoing major surgical resections for malignant disease. Neither the experience of the operating surgeon nor the prior administration of antibiotics had an effect on postoperative mortality.

A univariate analysis of the relationship of the 12 factors to postoperative mortality identified eight which were significantly related. All 12 factors, their frequency and the relationship to mortality are shown in Table 3. When adjustments were made for the interrelation of factors as in a multivariate analysis only three remained significant, an initial haematocrit of $30 \%$ or less $(p<0.0005)$, an initial plasma bilirubin of over $200 \mu \mathrm{mol} / \mathrm{l}(\mathrm{p}<0 \cdot 01)$ and a diagnosis of malignant obstruction $(\mathrm{p}<0.05)$. There was no effect on mortality of preoperative blood transfusion in

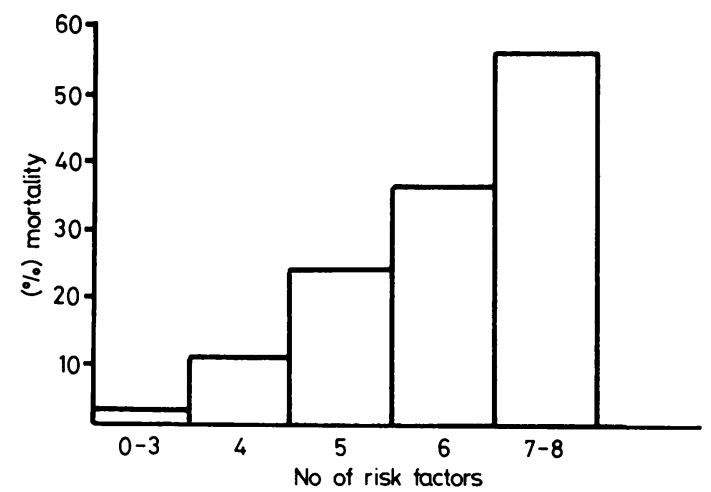

Fig. 1 Relationship of mortality and increasing numbers of unadjusted risk factors.

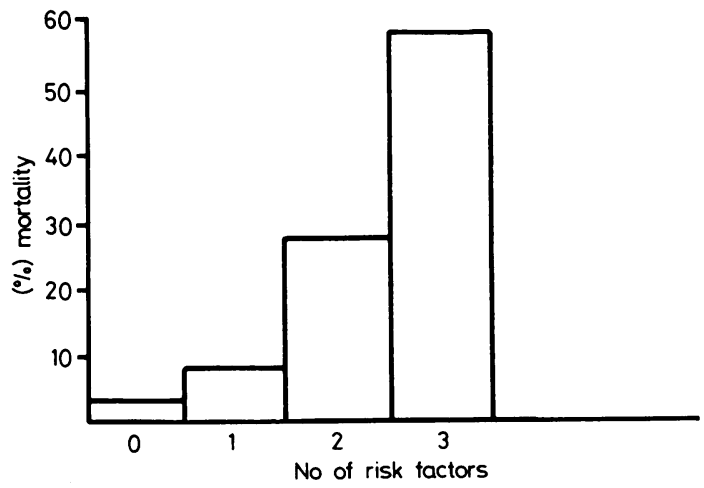

Fig. 2 Relationship of mortality and increasing numbers of adjusted factors. 
patients with an initial low haematocrit. Exclusion of the diagnosis from the analysis did not lead to any other factor becoming independently significant, but the effect of bilirubin increased relatively in significance $(\mathrm{p}<0.0005)$.

The correlation between the number of unadjusted risk factors per patient and mortality showed a significant increase in mortality when more than three factors were present, mortality increasing progressively in patients with increasing numbers of risk factors (Fig. 1). A similar stepwise progression was noted when mortality was compared with the three adjusted risk factors (Fig. 2). Increased mortality was seen in the 89 patients with two or three risk factors, with 29 out of the 34 deaths occurring in this group (Table 4), significantly different from the five deaths in the other 286 patients who had nil or one risk factor $(p<0.0005)$. One factor, a history of pancreatitis, was associated with a decreased likelihood of postoperative mortality $(p<0 \cdot 05)$.

The frequency of the seven postoperative complications specifically studied and their relationship to postoperative mortality is shown in Table 5. Three complications were associated with an increased risk of mortality, these being renal failure $(p<0.0005)$, gastrointestinal bleeding $(p<0.0005)$, and abdominal abscess $(p<0.05)$. Thirteen patients developed renal failure, of whom eight died and 27 developed postoperative gastrointestinal haemorrhage with 13 deaths.

Analysis of the three adjusted risk factors and postoperative complications (Table 6) showed that the frequency of renal failure and gastrointestinal bleeding increased in direct proportion to the number of adjusted risk factors present. Four other complications, wound infection, wound dehiscence, septicaemia, and abdominal abscess were significantly more common in the group of patients with one or more risk factors. The

Table 4 Risk factors (adjusted) and their relationship of postoperative mortality

\begin{tabular}{llcc}
\hline Risk factors (no.) & Patients (no.) & Deaths (no.) & Mortality (\%) \\
\hline $0+1$ & 286 & 5 & $1 \cdot 7$ \\
$2+3$ & 87 & 29 & $33^{*}$ \\
\hline
\end{tabular}

${ }^{*}$ Significantly different from groups of patients with 0 or 1 risk factors $(\mathrm{p}<0 \cdot 0005)$.

Table 5 Frequency of postoperative complications and their relationship to mortality

\begin{tabular}{|c|c|c|c|c|}
\hline \multirow[b]{2}{*}{ Complication } & \multicolumn{2}{|l|}{ Frequency } & \multicolumn{2}{|l|}{ Mortality } \\
\hline & Patients (no.) & $\%$ & Patients (no.) & $\%$ \\
\hline Renal failure & 13 & $3 \cdot 5$ & 8 & $61 \cdot 5+$ \\
\hline GI bleeding & 27 & $7 \cdot 2$ & 13 & $48 \cdot 1 \dagger$ \\
\hline Wound infection & 36 & $9 \cdot 7$ & 3 & $8 \cdot 3$ \\
\hline Wound dehiscence & 12 & $3 \cdot 2$ & 3 & $25 \cdot 0$ \\
\hline Septicaemia & 24 & $6 \cdot 4$ & 6 & $25 \cdot 0$ \\
\hline Abdominal abscess & 18 & $4 \cdot 8$ & 5 & $27 \cdot 8^{*}$ \\
\hline Pancreatitis & 14 & $3 \cdot 8$ & 2 & $14 \cdot 3$ \\
\hline
\end{tabular}

Mortality significantly different between those with and those without the complication: ${ }^{*} p<0 \cdot 05$; $+\mathrm{p}<0.0005$. 
Table 6 Relationship of the three adjusted risk factors and postoperative morbidity

\begin{tabular}{|c|c|c|c|c|}
\hline $\begin{array}{l}\text { Risk factors (no.) } \\
\text { Patients (no.) }\end{array}$ & $\begin{array}{r}0 \\
224\end{array}$ & $\begin{array}{r}1 \\
62\end{array}$ & 2. & $\begin{array}{r}3 \\
24\end{array}$ \\
\hline Complication & \multicolumn{4}{|c|}{$\%$ patients presenting with this complication } \\
\hline Renal failure & $0 \cdot 4$ & 1.6 & $7 \cdot 9 \ddagger$ & $25 \cdot 0 \S$ \\
\hline GI bleeding & 0.9 & $9 \cdot 7 \ddagger$ & $14 \cdot 3 \S$ & $41 \cdot 7 \S$ \\
\hline Wound infection & $7 \cdot 6$ & $22 \cdot 6 \ddagger$ & $3 \cdot 3$ & $12 \cdot 5$ \\
\hline Wound dehiscence & 0.9 & $6 \cdot 5^{*}$ & $3 \cdot 2$ & $16 \cdot 7 \S$ \\
\hline Septicaemia & 4.4 & $16 \cdot 1 \ddagger$ & $6 \cdot 3$ & 0.0 \\
\hline Abdominal abscess & 0.4 & $19 \cdot 3 \S$ & $6 \cdot 3+$ & $4 \cdot 1$ \\
\hline Pancreatitis & $4 \cdot 5$ & $3 \cdot 2$ & 1.6 & $4 \cdot 2$ \\
\hline
\end{tabular}

Significantly different from group of patients with 0 risk factors:

${ }^{*} \mathrm{p}<0.05 ;+\mathrm{p}<0 \cdot 01 ; \ddagger \mathrm{p}<0 \cdot 005 ; \S \mathrm{p}<0.0005$.

three septic complications were most commonly seen in elderly patients with a benign obstructing lesion, a bilirubin of $>200 \mu \mathrm{mol} / 1$ and the presence of bacteria in the bile and thus it is not surprising that the frequency of these complications was highest in the group of patients with only one major risk factor. The only complication which was seen with equal frequency in all groups of patients was postoperative pancreatitis.

\section{Discussion}

Mortality rates of between eight and $33 \%^{12}$ have been reported for surgery to relieve bile duct obstruction. It has been postulated that decompression of the obstructed biliary tree by external or internal biliary drainage by reducing bilirubin concentrations will reduce postoperative mortality and morbidity. ${ }^{16}$ The procedures of internal or external non-operative drainage are not without complications ${ }^{169-11}$ and thus are most appropriate in patients at high risk of postoperative mortality. ${ }^{3}$ Attempts to identify such patients have studied a series of preoperative factors in isolation, but all have failed to adjust for the inter-relationship of these factors. ${ }^{3-5}$ In this present series three independent risk factors were identified which were associated with a significantly increased risk of postoperative mortality, these being an initial haematocrit of $30 \%$ or less, an initial plasma bilirubin of greater than $200 \mu \mathrm{mol} / \mathrm{l}$ and a diagnosis of malignant obstruction. Patients with two or all three of these risks factors represent a group at high risk with a one third postoperative mortality, and it is this group of patients in whom preoperative or non-operative drainage might prove most useful.

The most significant of the three factors was an initial low haematocrit and the influence of haematocrit was not reduced by preoperative blood transfusion. A low haematocrit is likely to signify some degree of malnutrition. ${ }^{3}$ A period of preoperative drainage without full attention to the nutritional status of the patient is thus unlikely to have any influence on the predictive value of the initial low haematocrit. ${ }^{6}$

Internal or external biliary drainage will reduce plasma bilirubin, ${ }^{1}$ 6-8 which has been shown in this and other series to be an important factor in postoperative outcome. ${ }^{34}$ Reduction of plasma bilirubin below $200 \mu \mathrm{mol} / 1$ should on the basis of the present analysis lead to a reduction in operative mortality. 
The third factor, the diagnosis of malignant obstruction cannot be influenced and thus the mortality of operating on patients with a malignant obstructing lesion will remain significantly higher than patients with a benign obstruction. Few patients are suitable for resection and in the majority palliation is all that can be performed. ${ }^{14}$ In the latter group few patients survive longer than eight months. ${ }^{4}$ An alternative in this group of patients may be drainage with an internal biliary stent which appears to offer palliation similar to operative bypass, without the risk of operative mortality. ${ }^{78}$ Internal drainage, however, should only be performed after confirmation of the malignant nature of the obstruction by fine needle aspiration cytology.

Renal failure remains a problem in patients with obstructive jaundice, ${ }^{12} 13$ despite the use of mannitol. The frequency of this complication increases proportionately with the number of major risk factors present. The same association is seen with the other major complication related to mortality, gastrointestinal bleeding. ${ }^{4}{ }^{14}$ Attempts to improve nutrition, lower plasma bilirubin and avoid an unnecessary operation in at least some patients with malignant obstruction, should theoretically reduce the incidence of these potentially lethal complications.

The studies on preoperative biliary drainage remain ${ }^{16-10} 1516$ at present inconclusive with little data on randomised prospective trials available. ${ }^{16}$ From this study three major risk factors for operative mortality have been identified. A period of preoperative drainage with an attempt to improve nutritional status and control infection for patients with a benign obstructing lesion, a haematocrit of $30 \%$ or less and a plasma bilirubin of over $200 \mu \mathrm{mol} / 1$ should theoretically reduce operative mortality. Preoperative drainage can be achieved either by insertion of a percutaenous catheter, a duodenoscopically placed endoprosthesis or by endoscopic papillotomy. Similarly in patients with malignant disease and one or both of the other risk factors preoperative drainage (internal or external) or the avoidance of operation by the insertion of an internal stent with measures to improve nutrition and control infection should likewise reduce postoperative mortality. It remains to be seen whether more careful selection of patients for these drainage procedures will lead to a significant reduction in overall mortality and morbidity.

Departments of Clinical Surgery,

J M DIXON, C P ARMSTRONG, $S$ W DUFFY, AND

G C DAVIES

and Medical Computing and Statistics,

University of Edinburgh,

Edinburgh

Thanks are recorded to Miss $\mathrm{C}$ Hughes for secretarial assistance.

Address for correspondence: Dr J M Dixon. Department of Clinical Surgery, Royal Infirmary, Edinburgh EH3 9YW. 


\section{References}

1 Nakayama T, Ikeda A, Okuda K. Percutaneous transhepatic drainage of the biliary tract. Technique and results in 104 cases. Gastroenterolgy 1978; 74: 554-9.

2 Buckwater JA, Lawton RL, Tidrick RT. Bypass operation for neoplastic biliary tract obstruction. Am J Surg 1965; 109: 100-5.

3 Pitt HA, Cameron JL, Postier RG, Gadacz TR. Factors affecting mortality in biliary tract surgery. Am J Surg 1981; 141: 66-72.

4 Sato T, Saitoh Y, Koyama K, Watanabe K. Preoperative determination of operability in carcinoma of the pancreas and the periampullary region. Ann Surg 1968; 168: 876-86.

5 Braasch JW, Gray BN. Considerations that lower pancreaticoduodenectomy mortality. Am J Surg 1977; 133: 480-4.

6 Denning DA, Molnar W, Carey LC. Preoperative pecutaneous transhepatic biliary decompression lowers operative mortality in patients with obstructive jaundice. Am J Surg 1981; 141: 61-5.

7 Osnes M, Odd G, Gronoeth $\mathrm{H}$. Non operative internal drainage of obstructed common bile ducts. Arch Surg 1979; 114: 862-5.

8 Ferrucci JT Jr, Mueller PR, Harbin WP. Percutaneous transhepatic drainage: technique, results and applications. Radiology 1980; 135: 1-14.

9 Mori K, Misumi A, Suziyama M et al. Percutaneous transhepatic bile drainage. Ann Surg 1977; 185: 111-5.

10 Burcharth F, Efsen F, Christiansen LA et al. Non-surgical internal biliary drainage by endoprosthesis. Surg Gynecol Obstet 1981; 153: 857-60.

11 Armstrong CP, Taylor TV. Intrapleural leakage of bile complicating percutaneous transhepatic drainage of the obstructed biliary tree. $J$ R Coll Surg Edinb 1982; 27: 308-9.

12 Dawson JL. Postoperative renal function in obstructive jaundice: effect of mannitol diuresis. Br J Surg 1966; 53: 979-85.

13 Allison MEM, Prentice CRM, Kennedy AC, Blumgart LH. Renal function and other factors in obstructive jaundice. Br J Surg 1979; 66: 391-7.

14 Zollinger RM, Williams RD. Appraisal of progress in sugical therapy: surgical aspects of jaundice. Surgery 1956; 39: 1016-30.

15 McPherson GAD, Benjamin IS, Habib HA, Bowley NB, Blumgart LH. Percutaneous transhepatic drainage in obstructive jaundice: advantages and problems. Br J Surg 1982; 69: $261-4$.

16 Hatfield ARW, Tobias R, Terblanche $\mathrm{J}$ et al. Pre-operative external biliary drainage in obstructive jaundice: a prospective controlled clinical trial. Lancet 1982; 2: 896-9. 